\title{
Weather and sex ratios of head-started Agassiz's desert tortoise Gopherus agassizii juveniles hatched in natural habitat enclosures
}

\author{
Kenneth A. Nagy ${ }^{1,}{ }^{*}$, Gerald Kuchling ${ }^{2}$, L. Scott Hillard ${ }^{1}$, Brian T. Henen ${ }^{3}$ \\ ${ }^{1}$ Department of Ecology and Evolutionary Biology, University of California, Los Angeles, California 90095-1606, USA \\ ${ }^{2}$ School of Animal Biology, The University of Western Australia, Crawley, Western Australia 6009, Australia \\ ${ }^{3}$ Natural Resources and Environmental Affairs, MAGTFTC MCAGCC, Twentynine Palms, California 92278, USA
}

\begin{abstract}
Head-starting of Agassiz's desert tortoise, a means to aid recovery of this threatened species, may adversely affect offspring sex ratios via temperature-dependent sex determination combined with possible unnatural thermal conditions in head-start facilities. We determined sex ratios in juvenile tortoises hatched from first clutches of 4 annual cohorts at the head-start facility at the US Marine Corps Base, Twentynine Palms, California, USA, using non-fatal, endoscopic inspection of gonads. Cohort sexes ranged from $97 \%$ females (o: $0^{7}$ ratio of 6.25:1) in 2008 to $84 \%$ males (o: $0^{7}$ ratio of 0.19:1) in 2009, apparently primarily in response to local weather conditions during the temperature-sensitive phase of incubation. Warmer weather during development of a second clutch laid in 2009 led to fewer males (55\%, o: : $0^{\mathbb{T}}$ ratio of 0.82$)$. Efforts to cool (artificially shade) some nesting burrows were unsuccessful in increasing the proportion of male hatchlings in 2009. Cohort sex ratios were associated with average daily air temperatures during incubation, such that more females were produced during warmer periods, in good agreement with published temperaturecontrolled laboratory experiments. These results suggest that weather played a major role in determining sex ratios, with apparently smaller or negligible influences resulting from initial location, structure and operation of the head-start facility; experimental shading of nests; and individual mothers' variation in the timing of egg laying and placement of nests within the natal burrows. These results, obtained from a remote, mostly natural field site, indicate the potentially great sensitivity of sex determination in nests of wild, free-living desert tortoises to changes in climate.
\end{abstract}

KEY WORDS: Agassiz's desert tortoise - Climate change - Conservation · Head-start - TSD . Temperature-dependent sex determination $\cdot$ Weather

\section{INTRODUCTION}

Agassiz's desert tortoise Gopherus agassizii (Murphy et al. 2011), which inhabits the Mojave and Colorado Deserts in California, Nevada, Utah and Arizona, was listed as a threatened species in 1990 (US Fish and Wildlife Service 1990) following major declines in densities of populations in the western part of the species' range. The recovery plan for the species (US Fish and Wildlife Service 1994) recommended that research evaluate 'recruitment and

${ }^{*}$ Corresponding author: kennagy@biology.ucla.edu survivorship of younger age classes' and 'reproductive behavior and physiology', among other recommendations. The reproductive cycle of desert tortoises is similar to that of other Gopherus species, with nesting and egg laying beginning in late spring, incubation lasting much of the summer, and courtship and mating occurring mostly in autumn (Rostal 2014). The revised recovery plan (US Fish and Wildlife Service 2011a) recommended evaluating the efficacy of population augmentation efforts via release of head-started juveniles. 
The head-starting method usually begins with obtaining eggs and then hatching them indoors in containers (e.g. Wibbels 2003, 2007), or in nests in soil in outdoor enclosures (Nagy et al. 2015a,b). These procedures may alter the incubation temperatures of the eggs compared to temperatures in natural, unmanipulated nests (Baxter et al. 2008). This is important because the sex of a desert tortoise is determined by the temperature of the egg during the second quarter of development (temperature-dependent sex determination, or TSD; see reviews by Rostal 2014, Janzen \& Paukstis 1991). The pivotal temperature, yielding a 1:1 sex ratio among hatchlings experiencing constant incubation temperatures, is $31.3^{\circ} \mathrm{C}$, whereas constant temperatures below $30.5^{\circ} \mathrm{C}$ produce all males, and temperatures at or above $32.5^{\circ} \mathrm{C}$ produce all females (Rostal et al. 2002, Rostal \& Wibbels 2014). Thus, head-starting efforts may unintentionally yield hatchling tortoises that have undesirable sex ratios (e.g. all male or all female cohorts), as a result of inappropriate positioning of, and temperature influences on, incubating eggs. Moreover, global climate changes are already influencing wild populations of reptiles with TSD by increasing the proportion of females among recent offspring (e.g. Hays et al. 2010, Mitchell \& Janzen 2010, Patino-Martinez et al. 2012), and G. agassizii may experience ambient temperature increases of $1-3^{\circ} \mathrm{C}$ in the next 100 yr (Barrows 2011, Barrows et al. in press). Head-starting may offer ways to counter a climate-change-induced tendency toward excess recruitment of female chelonians in wild populations. This could be done by reducing nest temperatures in head-start facilities via added shading (Patino-Martinez et al. 2012), locating nests in cooler (deeper, wetter, or greater natural shading) soils, or by placing eggs in air-conditioned spaces.

The tortoise head-starting facility we used consisted of 4 fenced and netted predator-resistant enclosures built to enclose natural tortoise habitat within the largest population of tortoises at the Marine Corps Air Ground Combat Center (MCAGCC), Twentynine Palms, California, USA. Local wild females were used as egg donors. In spring, we moved them to pens inside the facility, where they dug nests and laid their eggs. The facility's location was chosen mainly on the basis that it is healthy tortoise habitat and is relatively safe from human disturbance. Because we recognized the potential for obtaining unnatural (strong deviation from 1:1) sex ratios, we examined the hypothesis that the one specific location of the facility, an exposed, sparsely vegetated (i.e. desert) flat area on top of a broad hill, could induce atypically high soil temperatures in nests and yield female-biased sex ratios in off- spring. We used endoscopy to evaluate sex ratios in 4 annual cohorts of juveniles (2006, 2007, 2008 and 2009). Based on the results from the first 3 years, which yielded increasing proportions of females, we attempted to experimentally manipulate the sex ratio of hatchlings in 2009 by shading a number of nest sites during the embryo development period. We also evaluated ambient temperatures using data from a nearby official weather station at MCAGCC.

\section{MATERIALS AND METHODS}

\section{Study site}

We built 4 fenced enclosures in open Mojave Desert habitat in the southwestern corner of the MCAGCC, WNW of Twentynine Palms, San Bernardino County, California. The enclosures of this head-start facility (the Tortoise Research and Captive Rearing Site [TRACRS]), contain natural vegetation consisting of a creosote bush Larrea tridentata-burro bush Ambrosia dumosa plant community, with naturally growing native food plants of desert dandelion Malacothrix glabrata, pincushion Chaenactis fremontii, plantain Plantago ovata and other species. Fencing of the first three $30.8 \times 46.2 \mathrm{~m}$ enclosures was constructed of 6-mm-square galvanized mesh screen buried $30 \mathrm{~cm}$ deep and extending $62 \mathrm{~cm}$ above ground (to exclude small animals), topped by cyclone fencing (5.1 cm mesh) 1.22 or $1.52 \mathrm{~m}$ high to exclude more mobile predators. A layer of smooth metal flashing $0.51 \mathrm{~m}$ high was installed above the mesh screen to exclude climbing rodents. A short, $30 \mathrm{~cm}$ high fence of $25 \mathrm{~mm}$ mesh poultry netting was installed approximately $1 \mathrm{~m}$ outside the enclosures to inhibit wild tortoises from physically contacting and transmitting diseases to tortoises inside the enclosures. The fourth enclosure, $30.8 \times 92.4 \mathrm{~m}$, had walls of r-panel (corrugated) metal sheeting rather than screening. Netting $(5.1 \mathrm{~cm}$ mesh) covered all enclosures to exclude large, predatory birds (e.g. common ravens). We subdivided 2 of the 3 screened enclosures and half of the metal-walled enclosure into individual, $7.7 \times 7.7 \mathrm{~m}$ pens using metal sheeting buried $15 \mathrm{~cm}$ and extending $46 \mathrm{~cm}$ above ground (Fig. 1A). We dug 2 or 3 adult-tortoise-sized burrows in each pen for potential use by egg-donor female tortoises. The enclosures were fitted with irrigation sprinklers so that we could simulate rain as necessary to obtain and maintain a crop of annual food plants representative of a 'good wildflower' year, each year of the study, despite variation in natural rainfall. 


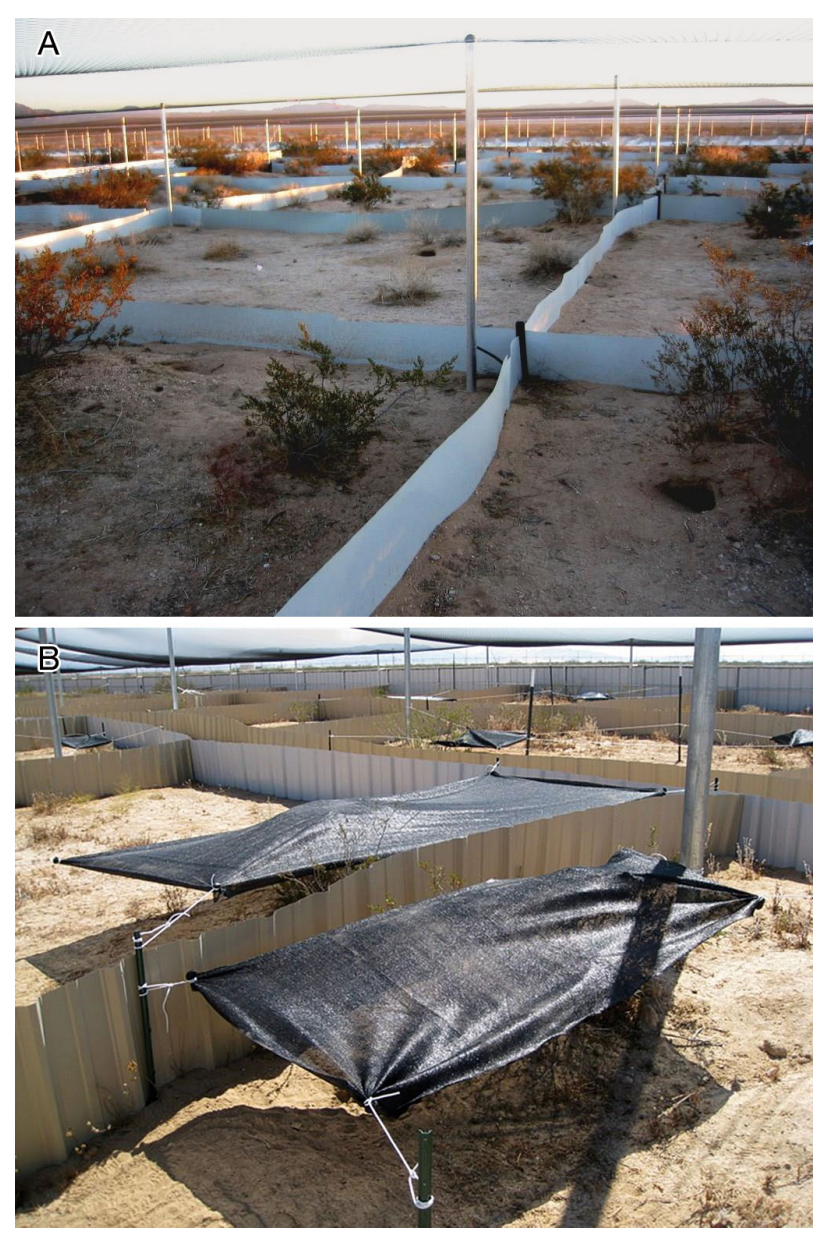

Fig. 1. (A) Head-start facility Enclosure 1 with subdivision panels (white metal flashing) and burrows provided for gravid females. (B) Shading of tortoise nest sites in Enclosure 4 of the head-start facility, the Tortoise Research and Captive Rearing site at the Marine Corps Air Ground Combat Center (MCAGCC), Twentynine Palms, California, USA

\section{Egg procurement}

Each spring from 2006 through 2009, we used Lotek receivers to locate wild, adult female tortoises that were wearing radio transmitters (model AI-2, Holohil Systems) and living near the head-start facility. We examined these individuals for clinical signs of upper respiratory tract disease in the field, took blood samples for laboratory analyses of antibodies for Mycoplasma spp. (Christopher et al. 1999, US Fish and Wildlife Service 2011b; M. agassizii and $M$. testudineum, as analyzed by Dr. Mary Brown at The University of Florida), and examined females for oviducal eggs (via palpation and primarily by $\mathrm{x}$-ray radiography; MinXray Portable models HF8015 and X750G; Wallis et al. 1999). We monitored gravid females (i.e. those that contained oviducal eggs) that were negative for Mycoplasma antibodies; when radiographs showed that oviducal eggs were moderately to heavily shelled (calcified), we brought the females to individual TRACRS pens to lay those eggs. These gravid females were free to use or modify the prepared burrows for nesting, or they could dig a new burrow and nest site. We intentionally did not monitor females close enough to observe where they located their nests in order to not influence when and where they laid their eggs. Also, we chose to not search through burrows and burrow soil to locate nests so as to avoid any disruption or accidental alteration of egg placement and nest conditions; disruption of nest soil can promote nest and hatchling predation by desert fire ants (Solenopsis xyloni; K. A. Nagy \& L. S. Hillard pers. obs.). These precautions precluded direct measurements of nest temperatures. Following egg laying, usually within 2 to 4 wk of transfer to TRACRS, we gave each female an opportunity to drink water, then we returned each to their home burrow for release and possible production of a second clutch of eggs.

\section{Shading experiments}

In spring of 2009, pieces of black shade cloth, approximately $4 \mathrm{~m}^{2}$ in area, were suspended approximately $0.5 \mathrm{~m}$ above every probable burrow nest site in 14 maternity pens shortly after the females laid their eggs (Fig. 1B). Another 10 nest burrows in nearby maternity pens were left unshaded, to act as controls. Soil surface temperatures in some shaded $(\mathrm{N}=8)$ and unshaded $(\mathrm{N}=9)$ areas were measured with a temperature gun (infrared thermometer, Raytek model ST ProPlus) during the morning warmup hours and again at night on 16 July 2010, which was roughly mid-way through the critical TSD period.

\section{Experienced female effects and second clutch observations}

Many of the egg-donor females participated in this study for several years. We noted whether 2009 cohort juveniles that we sexed came from mothers that had contributed eggs in previous years, and thus were familiar with our pens and procedures, or were females that were new to the study in 2009. In 2009, 12 females that were showing signs of producing a second clutch before release were retained to lay those eggs in our enclosures. 
Table 1. Numbers and ratios of female and male offspring in 4 annual cohorts of desert tortoises hatched from first clutches at the head-start facility, Tortoise Research and Captive Rearing Site (TRACRS). Chi-square $\chi_{1}^{2}$ tests indicate whether sex ratios differed from 1:1 for each year

\begin{tabular}{|ccccccccc|}
\hline & $\begin{array}{c}\text { No. of } \\
\text { offspring }\end{array}$ & $\begin{array}{c}\text { No. of } \\
\text { females }\end{array}$ & $\begin{array}{c}\text { No. of } \\
\text { males }\end{array}$ & $\begin{array}{c}\text { Females: } \\
\text { males }\end{array}$ & $\begin{array}{c}\% \\
\text { females }\end{array}$ & $\chi_{1}{ }^{2}$ & $p$ \\
\hline 2006 & 30 & 20 & 10 & $2: 1$ & 67 & 3.483 & 0.0658 \\
2007 & 29 & 25 & 4 & $6.25: 1$ & 86 & 15.786 & $<0.001$ \\
2008 & 37 & 36 & 1 & $36: 1$ & 97 & 34.056 & $<10^{-6}$ \\
2009 & 25 & 4 & 21 & $0.19: 1$ & 16 & 12.083 & $<0.001$ \\
\hline
\end{tabular}

\section{Sex determination}

For this study, we used 121 of the over 300 juveniles in 4 age cohorts (from hatching years 2006 to 2009, selecting approximately 30 juveniles per cohort; Table 1). The juveniles were hatched and subsequently lived in TRACRS enclosures (Fig. 1A) containing natural vegetation for food and natural soil for digging. The pens received natural rain, along with intermittent sprinkler irrigation provided only as necessary to keep annual food plants green and growing through spring. The gonads of these tortoises were observed and photographed via endoscopy to determine their sex. This procedure is described in detail for tortoises elsewhere (Kuchling et al. 2011, 2013, Kuchling \& Griffiths 2012), but a brief description follows. Juveniles that were 6 to 30 mo old were anesthetized with intravenous injections (carpal venous sinus) of $20 \mathrm{mg} \mathrm{kg}^{-1}$ ketamine. Optimum anesthetic depth was achieved after approximately $15 \mathrm{~min}$. Both hind legs were pulled backwards and tied together. The left inguinal pocket and neighboring skin, shell and leg were scrubbed with antiseptic soap and povidone-iodine. A small incision was then made in the skin cranial to the left hind leg and a blunt dissection facilitated endoscopic examination of the gonad with a $2.7 \mathrm{~mm}$ diameter rigid Stor Hopkins endoscope. The abdominal cavity was not insufflated. Gonads and accessory ducts were visualized and a digital camera (Nikon Coolpix 995) was used for photo documentation (G. Kuchling et al. unpubl. data). We closed the skin using a sterile, copolymer absorbable suture.

\section{Weather data}

We used daily minimum, maximum and average air temperatures recorded nearby at the Expeditionary Air Field of MCAGCC. This National Weather Service station (KNXP) is approximately $10 \mathrm{~km}$ from TRACRS and its elevation and topography are similar to those of TRACRS. We also summarized longterm (30 yr) air temperatures for this weather station for the analysis of ambient temperatures during the TSD-sensitive period. Carter et al. (2015) have shown that local weather information can reflect soil microclimates relatively accurately.

\section{Statistics}

Sex ratio results were analyzed for differences from 1:1 using chi-square tests with Yate's correction for continuity (Zar 1999), and among years or groups with a contingency table chi-square test. Average daily air temperatures, combined by week for the 8 wk between mid-May, June and mid-July (the first half of the incubation period for the first clutch of eggs) were compared between years using Student's t-tests, or by Mann-Whitney rank sum tests when distributions failed the Shapiro-Wilk normality test. Weekly mean air temperatures during the temperature-sensitive periods were compared between first and second clutches in 2009 using a paired $t$-test.

To evaluate whether temperature influenced offspring sex around a pivotal temperature, we used a 3-parameter sigmoidal (non-linear) regression model (SigmaPlot 11, Systat Software, 2008) to plot the percentage of females produced each year against air temperature $\left({ }^{\circ} \mathrm{C}\right)$ measured at the Expeditionary Air Field. We used the average daily air temperatures during the second quarter of egg incubation because nest temperatures during this period determined offspring sex in laboratory trials for G. agassizii (Rostal $\&$ Wibbels 2014). The dates of the second quarter of incubation in 2006 (10 June to 1 July), 2007 (23 June to 14 July), 2008 (30 June to 21 July) and 2009 (10 June to 1 July for the first clutches and 5 July to 26 July for the second clutches) were determined as the 23rd to 44 th day after the mean estimated date (range $\pm 5-7 \mathrm{~d}$ ) of egg-laying for each year (18 May in 2006, 30 May in 2007, 7 June in 2008, 18 May in 2009 first clutch, and 12 June in 2009 second clutch). The duration of one-quarter of the incubation period was estimated at $22 \mathrm{~d}$ from the 90 -d total length of incubation measured in desert tortoises' nests in natural habitat (Baxter et al. 2008). The 3-parameter sigmoidal model

$$
y=\frac{a}{1+\mathrm{e}^{-\left[\frac{\left(x-x_{0}\right)}{b}\right]}}
$$


where $y$ is \% females, $x$ is air temperature in ${ }^{\circ} \mathrm{C}$, $a$ is the curve's maximum or asymptote (approaching $100 \%$ females), $x_{0}$ is the $x$ value at the middle of the sigmoid (or inflection point) and $b$ is the steepness of the sigmoid regression, was the simplest model, and provided nearly identical results to higher parameter models, including logistic, Weibull, Gompertz and other models. The sigmoidal model

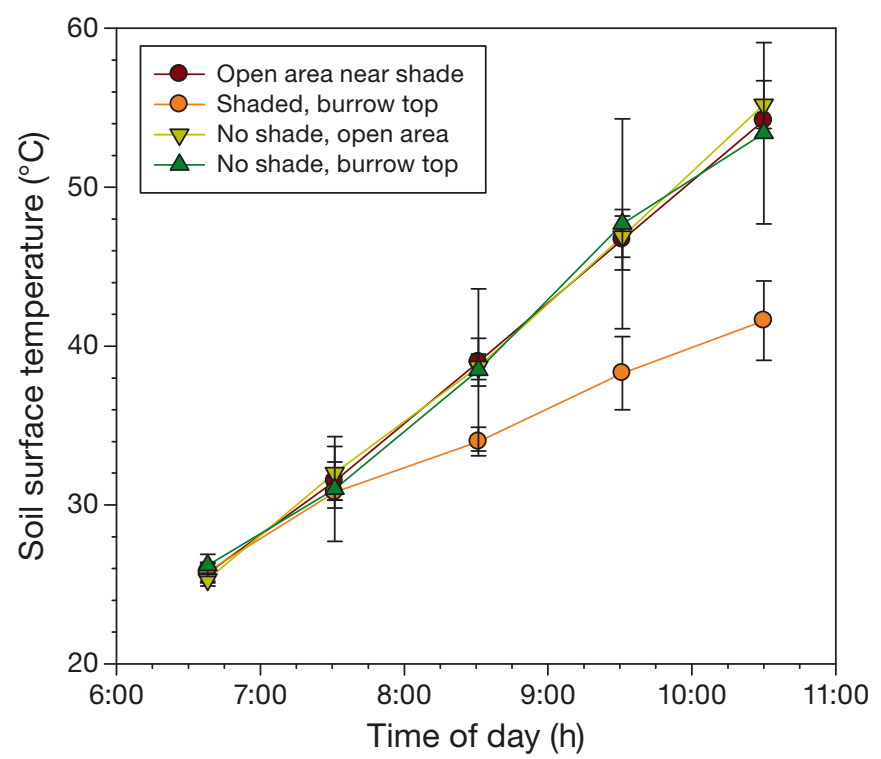

Fig. 2. Soil surface temperatures (mean $\pm \mathrm{SD}$ ) in adjacent open areas $(\mathrm{N}=17)$, and in the shaded $(\mathrm{N}=8)$ or unshaded $(\mathrm{N}=9)$ areas directly above presumed nest sites in burrows at the Tortoise Research and Captive Rearing Site (TRACRS). The sun rose at approximately 06:00 h, and all soil surfaces heated as the morning progressed, but surfaces above unshaded burrows (green line) remained thermally similar to adjacent open soil, whereas surface temperatures above shaded burrows (orange line) lagged progressively behind open soil surface temperatures

Table 2. Sex ratios and numbers of female and male desert tortoise offspring produced in the 2009 shading experiment, an attempt to manipulate sex ratios in the 2009 cohort. The frequency of females and males was evaluated with a simple chi-square $\chi_{1}^{2}$ test, with a probability of results not occurring due to chance (i.e. differing from 1:1 ratios). Also summarized are first and second clutch results, and results from females experienced with or new to the headstart facility and procedure

\begin{tabular}{|lcccccccc|}
\hline & $\begin{array}{c}\text { No. of } \\
\text { offspring }\end{array}$ & $\begin{array}{c}\text { No. of } \\
\text { females }\end{array}$ & $\begin{array}{r}\text { No. of } \\
\text { males }\end{array}$ & $\begin{array}{r}\text { Females: } \\
\text { males }\end{array}$ & $\begin{array}{c}\% \\
\text { females }\end{array}$ & $\chi_{1}{ }^{2}$ & $p$ \\
\hline All & 82 & 18 & 64 & $0.28: 1$ & 22 & 26.136 & $<10^{-6}$ \\
Shaded & 46 & 9 & 37 & $0.24: 1$ & 20 & 24.802 & $<10^{-5}$ \\
Unshaded & 36 & 9 & 27 & $0.33: 1$ & 25 & 9.286 & $<0.005$ \\
First clutch & 62 & 9 & 53 & $0.17: 1$ & 15 & 31.754 & $<10^{-6}$ \\
Second clutch & 20 & 9 & 11 & $0.82: 1$ & 45 & 0.238 & 0.626 \\
Experienced & 24 & 4 & 20 & $0.2: 1$ & 17 & 11.174 & $<0.001$ \\
New & 38 & 5 & 33 & $0.15: 1$ & 13 & 21.216 & $<10^{-5}$ \\
\hline
\end{tabular}

also accurately estimated the pivotal temperature $\left(x_{0}\right.$; $31.3^{\circ} \mathrm{C}$ ) for the incubation data summarized in Table 6.1 of Rostal \& Wibbels 2014 (original data from Spotila et al. 1994, Rostal et al. 2002). We also summarized the long-term air temperatures for this weather station. Statistical significance was accepted if the p-value was 0.05 or lower.

\section{RESULTS}

\section{Sex ratios}

The sex ratios increased from $67 \%$ female in 2006 to $97 \%$ in 2008 (Table 1), with ratios within years significantly different from 1:1 in 2007 and 2008, but marginally not so in 2006. In contrast, the 2009 cohort was mostly male (84\%; Table 1$)$, and the sex ratio was significantly different from 1:1 (Table 1). Sex ratios did not differ between 2006 and $2007\left(\chi_{1}^{2}=\right.$ 2.125, $\mathrm{p}=0.1449$ ), but differed among the first 3 years $\left(\chi_{2}^{2}=11.896, p=0.0026\right)$ and even more strongly among all 4 years $\left(\chi_{3}^{2}=51.872, \mathrm{p}<10^{-8}\right)$.

\section{Shading experiment}

\section{Soil surface temperatures}

Compared to open areas, shaded soil surfaces were much cooler near midday, but were similar (within $2{ }^{\circ} \mathrm{C}$ ) at night and in the early morning (Fig. 2). Daytime temperatures in the shade lagged progressively further behind those in the sun as the soil heated during morning hours. By 10:30 h, soil temperatures in shaded areas averaged $12.6^{\circ} \mathrm{C}$ cooler than the unshaded areas $\left(t_{32}=-9.51, \mathrm{p}<0.001\right)$, while temperatures in open areas and on top of unshaded burrows were similar (Kruskal-Wallis 1-way ANOVA on ranks, $H_{2}=1.64, \mathrm{p}=0.440$,).

\section{Experienced female and second clutch sex ratios}

In the 2009 cohort, the combined sex ratio (shaded plus unshaded) was approximately 1 female to 4 males (Table 2 ), the approximate inverse of the previous 3 years, and was significantly different from a 1:1 ratio. The switch to a male bias was not due to shading; 
shaded and unshaded clutches both produced predominantly males, and sex ratios of shaded and unshaded nests did not differ $\left(\chi_{1}^{2}=0.10, p>0.74\right)$. Juveniles from the second clutches of 2009 had a higher proportion of females than did first clutches $\left(\chi_{1}{ }^{2}=\right.$ $6.52, p<0.011)$. However, the offspring sex ratio did not differ between experienced females and females new to the head-starting facility pens (experienced and new, $\left.\chi_{1}{ }^{2}=0.0001, p=0.9904\right)$ : both groups had ratios significantly biased towards males (Table 2 ).

\section{Air temperature}

Average weekly air temperatures generally rose during spring and were high during summer (Fig. 3) before falling sharply in mid-September (Week 38). There was substantial variation in springtime and early summertime temperature between years, with June-July 2009 appearing to be cooler than in the previous 3 years. Statistical comparisons of daily average air temperatures, grouped by week, between 2009 versus 2006, 2007 and 2008 combined, revealed that temperatures in 2009 were significantly lower during the $5 \mathrm{wk}$ from the first week in June through the first week in July than in the previous 3 years (all $t>2.34$, all Mann-Whitney $U>10.0$, all $\mathrm{p} \leq 0.025$ ). No rain fell during May, June, July or August 2009, and we did not irrigate between early May and mid-October of 2009.

\section{Air temperature and sex ratios}

The relationship between offspring sex and average 24-h air temperature was similar to that for laboratory incubation studies of TSD (Fig. 4).

\section{DISCUSSION}

\section{Head-starting and sex ratios}

In reptiles with TSD, such as many turtles and tortoises, it is the temperatures of the embryos during development, rather than the embryos' chromosomes, that determine the sex of the offspring (Pieau 1976, Bull \& Vogt 1979, Janzen \& Paukstis 1991, Spotila et al. 1994, Rostal \& Wibbels 2014). This phenomenon may lead to problems in otherwise well-intended efforts to aid declining populations by protecting nests and eggs using predator-resistant natural field enclosures, or indoor incubation of eggs collected from the nests (e.g. sea turtles, see review by Siegel

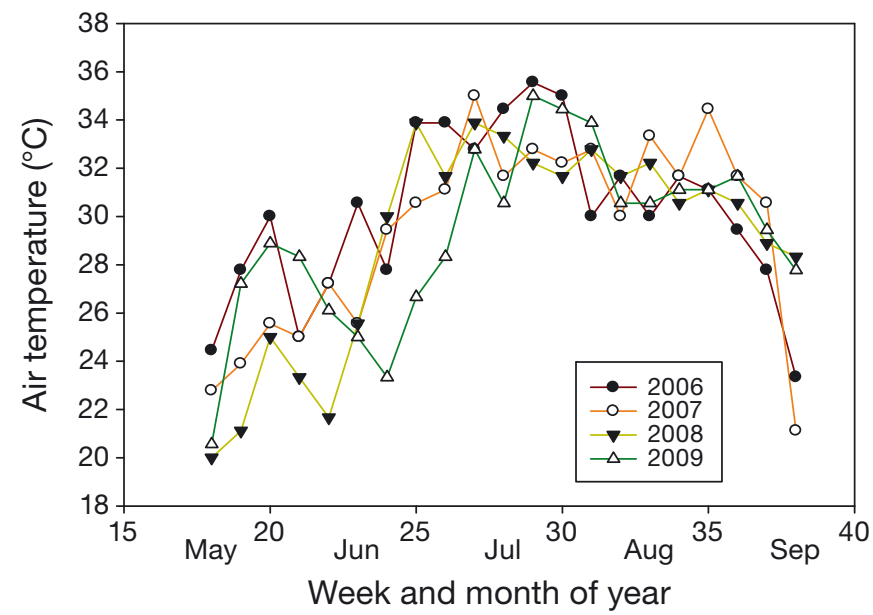

Fig. 3. Weekly means of average daily air temperatures $\left({ }^{\circ} \mathrm{C}\right)$ from May through September during 4 consecutive years at

MCAGCC's airfield, $10 \mathrm{~km}$ from the head-start facility

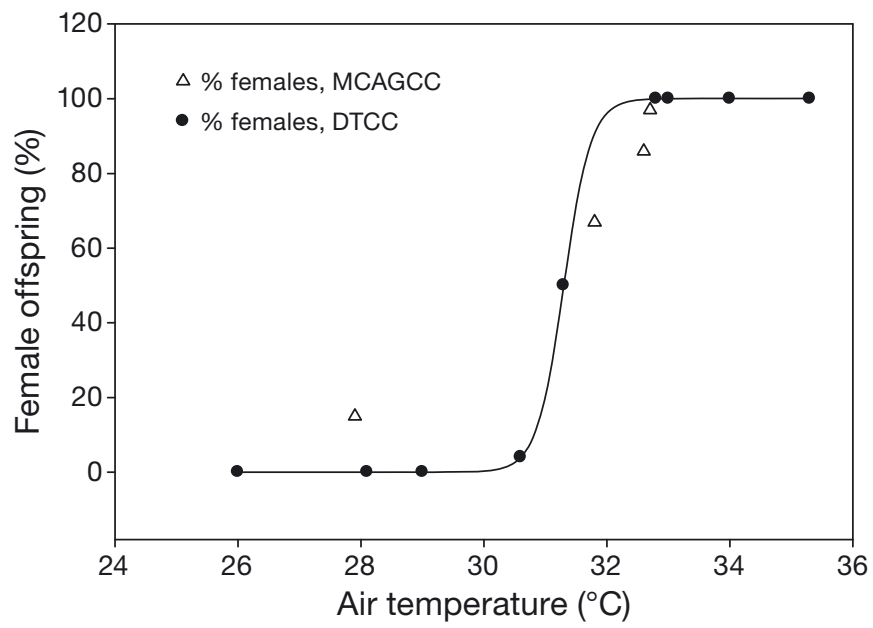

Fig. 4. The percent female composition of the 2006-2009 hatchlings from natural nests at MCAGCC (triangles) varied with average air temperature as measured at a nearby weather station, and generally followed the trend seen in constant-temperature incubation experiments done on eggs from tortoises at the Desert Tortoise Conservation Center (DTCC) near Las Vegas, Nevada (Table 6.1 in Rostal \& Wibbels 2014), which had sigmoidal regression coefficients of $100.0 \%$ (asymptote), 0.220 (steepness) and $31.3^{\circ} \mathrm{C}$ (inflection point at $50 \%$ females), and ANOVA results of $F_{2,6}=7,25$ $\times 10^{6}$ and $\mathrm{p}<10^{-8}$. The estimated pivotal temperature, at which the sex ratio is $50 \%$ female, was $31.3^{\circ} \mathrm{C}$ for incubator studies (Rostal et al. 2002, Rostal \& Wibbels 2014). There were too few data to generate a statistically significant sigmoid regression and pivotal temperature estimate for the field data $\left(F_{2,3}=50.8, \mathrm{p}=0.0987\right)$

\& Dodd 2000). Such head-start facilities and associated procedures may inadvertently influence the temperatures of developing embryos and thereby affect the sex ratios of the progeny in an unnatural or undesirable way. Examples include building a field hatchery in an unusually warm or cool microhabitat 
within the species' natural habitat (Grosse et al. 2015), influencing or restricting pregnant female tortoises from laying their eggs when or where they choose inside the fenced enclosures, disturbing the nest environment after eggs have been laid in ways that may affect subsequent nest temperatures, such as by influencing wind currents, sun exposure or precipitation around the nest, and incubating eggs indoors at inappropriate temperatures.

To evaluate whether the TRACRS head-start facility was yielding undesirable sex ratios (i.e. substantially different from 1:1 o: $0^{7}$ ) among the resulting juveniles, we determined the sex of offspring in samples from 3 consecutive cohorts. The results for 2006, 2007 and 2008 were alarming: most juveniles were females, and the proportion of females increased from $67 \%$ in 2006 to nearly $100 \%$ in 2008 . We suspected that we had head-starting facility issues as described above, and extended the study for a fourth year to conduct a manipulation experiment designed to yield more males. However, the results for 2009 showed that male-biased sex ratios can occur at TRACRS, allaying our concerns about undesirable thermal consequences of the facility site, structure or operation. Secondly, the intentional and continuous shading of nests did not shift sex ratios toward more males. These observations prompted us to examine alternate interpretations of sex ratio variation.

\section{Sex ratio variation}

What could account for the wide sex ratio variation that we measured among years? Possible factors include the TRACRS facility (i.e. variation in effects of enclosure structures on thermal conditions in nests), nesting behavior of egg-donor females (e.g. variation in nesting dates or nest site selection within or among females that we used in different years), and annual variation in ambient temperatures.

\section{Location and structure effects}

The TRACRS site and its physical structure were probably not important in influencing the sex ratios of hatchlings. Sex ratios of first clutches varied from nearly all female (97\%) offspring to mostly male ( $85 \%$ ) offspring during 2 consecutive years (2008 and 2009), but the facility and operations remained unchanged during all years. Statistically, the location, structure and operations did not cause consistently female-biased sex ratios.

\section{Female nesting behavior}

Can variation in female nesting behavior account for the variation in hatchling sex ratio? Our rough estimates of egg-laying times suggest that firstclutch nests were laid approximately 2 wk earlier in 2006 and 2009, when the most male hatchlings were produced, than in 2007 and 2008, when mostly females were produced. It is possible that female choice of laying dates accounted for this, but it is also possible that variation in the weather was responsible. High temperatures in mid-May 2006 and 2009, but not in 2007 and 2008 (Fig. 3), may have helped females lay early those years; also, 2007 was an extremely dry year, with little to no availability of preferred food plants (annual wildflowers). In a 7-yr field study (Lovich et al. 2012), first clutch appearance was later in cool years relative to warm years. Early laying also appears to help females produce second clutches (Karl 1998, Wallis et al. 1999), and may increase the variation in sexes for a year in which 2 clutches are produced.

It is also possible that females chose burrow nesting sites with varied thermal conditions in a way that could account for the observed variation in sex ratios among years. Baxter et al. (2008) reported that natural nests in their study were located mostly between 0.7 and $0.9 \mathrm{~m}$ down from the entrance of adult burrows and buried $8-10 \mathrm{~cm}$ deep in soil; this is consistent with hundreds of nests excavated at the Desert Tortoise Conservation Center (Las Vegas, Nevada; B. T. Henen pers. obs.). Our casual observations of nest locations at MCAGCC and observations at 2 sites in the eastern Mojave Desert (B. T. Henen unpubl., A. E. Karl unpubl.) agree with the nest placement recorded by Baxter et al. (2008). Baxter et al. (2008) also measured temperatures in pseudo-nests they dug closer (than $0.7 \mathrm{~m}$ ) to the burrow entrance, and found that temperatures there became too high for eggs to survive. Thus, choice of nest location within burrows may be restricted to deeper, less thermally stressed locations, and females do dig nests deeper than $0.9 \mathrm{~m}$ from the entrance (Baxter et al. 2008, B. T. Henen pers. obs.).

The surface temperatures we measured, shaded or unshaded (Fig. 2), also suggest that nests which were dug outside the burrows would be only 8 to $10 \mathrm{~cm}$ from the surface, thus threatening the eggs with lethally high temperatures. We have observed hundreds of nest holes, but none were dug outside of burrows; however, some nests have been dug outside burrows at sites with cooler summer temperatures (Ennen et al. 2012). Nesting within burrows seems to 
protect nests from lethal temperatures and from easy access to predators, but temperatures along the length and depth of burrows warrant more study. This is particularly important if deserts warm by $1-3^{\circ} \mathrm{C}$ in the next century (see discussion by Barrows et al. 2016), as such a temperature increase approximates the shift from all-male temperatures $\left(30.5^{\circ} \mathrm{C}\right)$ to all-female temperatures $\left(32.5^{\circ} \mathrm{C}\right.$; Rostal et al. 2002, Rostal \& Wibbels 2014).

Moreover, results from our shading experiment imply that female choice of shrub-shaded versus more exposed burrows may also have little effect on hatchling sex ratios. This suggestion is supported by the finding by Baxter et al. (2008) that nest temperatures and sex ratios of $G$. agassizii hatchlings were independent of the compass orientation of the nest burrows. Apparently, females place nests far enough below ground level that daytime variations in surface temperatures do not influence nest temperatures substantially: daily soil temperature variation was not detectable at $60 \mathrm{~cm}$ depth (Porter et al. 1973). However, in some turtle species, variation in nest site shading can have a substantial effect on sex ratios (painted turtles Chrysemys picta bellii, Janzen 1994; and green turtles Chelonia mydas, Morreale et al. 1982), as some of these nests, especially C. picta nests, may not reach soil depths of $60 \mathrm{~cm}$.

Another clue that nesting behavior differences were not a major factor was the lack of a significant difference between sex ratios in the first clutches of experienced females and inexperienced females (Table 2). Females that donated eggs successfully at TRACRS were usually placed back in the same pen in subsequent years, and their behavior did not suggest stress. However, unsuccessful donors frequently paced in their pens, held clutches longer than did successful layers, and often laid no eggs until released back at their homes in the field. Also, one might assume that experienced females would be more likely to show nesting adjustments in comparison to new females, but that did not happen in a manner that influenced offspring sex ratios.

No other such field studies on desert tortoises, or on the other 4 species of Gopherus tortoises, are available for comparison (see Rostal \& Wibbels 2014). However, studies of C. picta have also concluded that gravid females may not have the opportunity to alter clutch sex ratios (Refsnider \& Janzen 2012) or may not adjust their nesting behavior sufficiently to alter sex ratios substantially (Schwarzkopf \& Brooks 1987, Schwanz \& Janzen 2008, Mitchell \& Janzen 2010, Renfsnider et al. 2013). This supports the conclusion that weather may dominate the sex ratios of hatchling cohorts.

\section{Female reproductive biology}

Do egg-donor females tend to produce the same sex of offspring, and in 2009 did we inadvertently pick females that tend to produce only male offspring? We tested this suggestion by comparing the sex ratios of the clutches produced by individual donor females in both 2008 and 2009. Of the 11 females in 2008 and 17 females in 2009 that contributed 2 or more hatchlings for which sex was determined (thereby allowing a clutch sex ratio to be calculated), 5 females contributed in both years. In 2008, all 5 mothers produced $100 \%$ female clutches ( $N=17$ sexed juveniles), and the same 5 females produced $100 \%$ male clutches in 2009 ( $N=18$ sexed juveniles). Thus, we detected no pattern suggesting individual mothers favored a single sex of offspring. This result is consistent with other temperature effects indicated and suggests the strong effect of weather on hatchling sex ratios.

\section{Ambient temperature effects}

The similarity in the ambient temperature effects on sex ratios between laboratory and field enclosure juveniles (Fig. 4) suggests that wild populations of $G$. agassizii experience the same temperature effects that were demonstrated in thermally controlled, laboratory incubation studies, and that natural, annual fluctuations in temperature affect offspring sex in the wild. This observation, along with the lack of effects of pen location, pen structure, female behavior or rainfall, suggests that a parsimonious interpretation of these results is that natural variation in temperature conditions during this study strongly influenced hatchling sex ratios. Thus, future head-start programs that are designed to incorporate natural conditions as much as possible, such as this one, may produce cohort sex ratios that are strongly influenced by weather or climate cycles. However, the 'bet-hedging' tendency of females to produce eggs every year (Henen 1997, Lovich et al. 2015) should help individual females produce a mix of male and female offspring over their reproductive lifespans, given yearto year variation in seasonal ambient temperatures. Nevertheless, if climate changes cause a consistent warming trend in the Mojave Desert during spring and summer, desert tortoises may unavoidably produce higher proportions of female offspring.

Precipitation events that occur during the sexdetermining phase of incubation may cause cooling of nests and alter clutch sex ratios toward predominantly males. Loggerhead turtle nests had lower 
temperatures and produced more males in wet years (Lolavar \& Wyneken 2015), and some Southern River turtle (Batagur affinis) nests had lower temperatures after heavy rains, and those nests produced males (G. Kuchling and E. H. Chan, pers. obs.). However, the predominance of male desert tortoise juveniles in our 2009 cohort was not due to precipitation: there were no rain or irrigation events between early May and late August 2009 at TRACRS.

We explored the possible influence of weather variation on sex ratio of neonate tortoises by examining 30-yr weather records (1986-2015) from the nearby Expeditionary Air Field. The median beginning and ending dates for the second quarter of development from our study were 18 June and 9 July, respectively. Using the average daily air temperatures for these $22 \mathrm{~d}$, for 1986 to 2015 (online from Weather Underground, https://www.wunderground.com/history/ airpot/KNXP/2006/6/26/MonthlyHistory.html?\&reqdb. zip $=\&$ regdb.wmo=; data were missing for some years), we calculated the mean for each year. The comparison between these ambient temperatures and the pivotal temperature of $31.3^{\circ} \mathrm{C}$ (Fig. 5) indicates that year-to-year temperature variation may have major effects on the sex of offspring. If we use the upper $\left(32.5^{\circ} \mathrm{C}\right)$ and lower $\left(30.5^{\circ} \mathrm{C}\right)$ limits for generating all females and all males, respectively (Rostal et al. 2002; Rostal \& Wibbels 2014), 5 of 23 years (ca. 22\%) would have first clutches that generate all female hatchlings, 10 of 23 years (ca. $43 \%$ ) would have first clutches that generate all male hatchlings, and the remaining 8 years $(35 \%)$ would have first clutches that are mixtures of female and male offspring. An oversimplistic interpretation, assuming equal egg production among years, would suggest that there has been a recent environmental (i.e. ambient temperature) bias towards generating male hatchlings. However, egg production and clutch frequency vary considerably among years and sites, with increases in both during wet years (e.g. El Niño years; see Turner et al. 1986, Henen 1997, Mueller et al. 1998, Wallis et al. 1999, Lovich et al. 2015). This variation, plus the unknown juvenile survivorship that may vary between sexes (males obtain larger body sizes), probably also influences sex ratios within populations. For this 30 -yr period, there was no trend toward increasing incubation-period temperatures that may be consistent with a warming climate (see Barrows 2011, Lovich et al. 2014).

Due to our 'do not disturb nesting females or nests' protocol, we did not measure nest temperatures in this study, but nest temperatures of Agassizi's desert tortoises were measured by Baxter et al. (2008) under mostly natural conditions at a similar head-start facil-

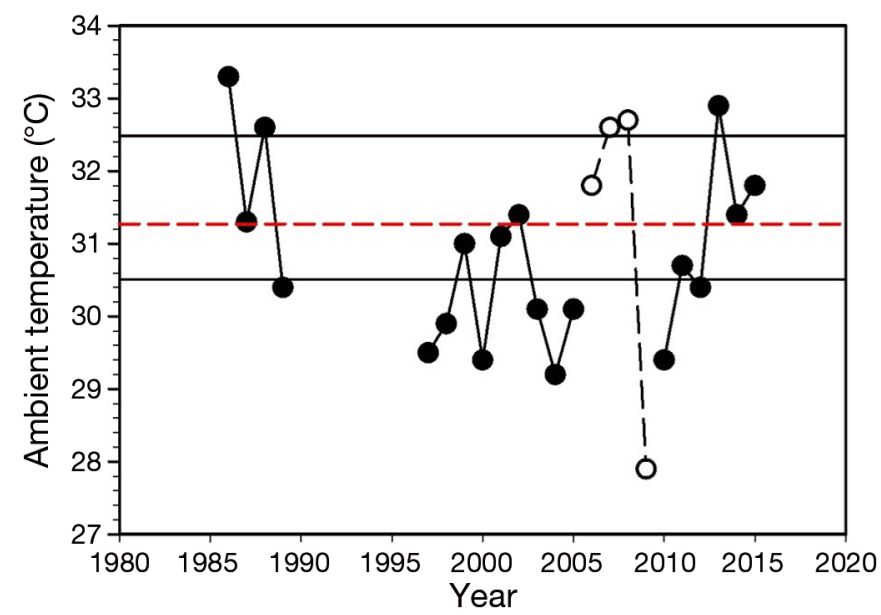

Fig. 5. Ambient temperature during the 22-d second quarter of the predicted first-clutch incubation period for desert tortoise nests at the head-start facility, TRACRS. Closed circles indicate the mean of the 22 daily average air temperatures from 18 June to 9 July each year measured $10 \mathrm{~km}$ from TRACRS (data for 1990-1996 were unavailable). Open circles indicate the same temperatures for the 4 years of the present study, but for the approximate dates of each year's actual incubation period, which differed year to year (see 'Statistics' for dates). The 18 June to 9 July interval used for other years is the average of the 4 study years (2006-2009). Dashed red line indicates the laboratory-determined, pivotal sex-determining temperature of $31.3^{\circ} \mathrm{C}$ (Rostal \& Wibbels 2014)

ity in the Mojave Desert. They found that 6 clutches laid early (late May and early June) had midincubation-period nest temperatures significantly lower than did 5 clutches laid later (mid-June to early July), when ambient air temperatures were higher. The early (cooler) clutches produced $75 \%$ male hatchlings whereas late (warmer) clutches that same year produced all females. The observations of Baxter et al. (2008) are consistent with laboratory results and with findings reported herein, and they add important details about nest temperatures under field conditions.

\section{CONCLUSIONS}

Factors other than the physical properties of the head-start facility, and other than the nesting behavior or other reproductive characteristics of egg-donor females, were more important in sex determination of offspring produced at TRACRS. Present evidence implicates local weather conditions during the late spring and early summer incubation period as a major determinant of sex ratios of desert tortoise hatchlings. 


\section{Conservation implications}

The correspondence between sex ratios and environmental temperatures suggests that natural variation in weather produces a range of sex ratios in wild populations of the desert tortoise. It also suggests that a general habitat warming due to climate change may have unhealthy long-term effects on sex ratios in head-started desert tortoises, as well as in wild tortoise populations. The apparently minimal ability of gravid females in this study to influence the sex ratios of their clutches is a concern, as is our inability to influence clutch sex ratios via local shading of nest burrows. Larger-scale shading or irrigation of pens to cool nests during the incubation period may be worth further study. We must also determine whether there is differential survivorship of sexes before and after reaching maturity so we may more accurately target the optimal blend of sex ratios for a long-term stable population of tortoises.

Acknowledgements. This research was funded by the US Marine Corps, Natural Resources and Environmental Affairs Division at MCAGCC via Grant W911NF-05-1-0220 through the US Army Research Office. We are grateful to Marie Cottrell, Major John Aytes and Rhys Evans for help with funding and logistic support, Russell Harmon (US Army) for facilitating funding efforts, Mary Brown for testing blood samples for Mycoplasma sp. antibodies, Brent Husung and Guundie Kuchling for help in the field, the MCAGCC Roads and Grounds Crew for water deliveries, Salvatore and Mary Lou Sortino for logistical support, Charles Peterson for valuable comments that improved the manuscript, and Roy Averill-Murray for advice on obtaining permits. This research was conducted under permits from the US Fish and Wildlife Service (Native Threatened Species recovery permit TE-085050), the California Department of Fish and Wildlife (Scientific Collecting Permit SC001954) and the UCLA Animal Research Committee (ARC 1992-057).

\section{LITERATURE CITED}

Barrows CW (2011) Sensitivity to climate change for two reptiles at the Mojave-Sonoran Desert interface. J Arid Environ 75:629-635

Barrows CW, Henen BT, Karl AE (2016) Identifying climate refugia: a framework to inform conservation strategies for Agassiz's desert tortoise in a warmer future. Chelonian Conserv Biol 15:2-11

> Baxter PC, Wilson DS, Morafka DJ (2008) The effects of nest date and placement of eggs in burrows on sex ratios and potential survival of hatchling desert tortoises, Gopherus agassizii. Chelonian Conserv Biol 7:52-59

Bull JJ, Vogt RC (1979) Temperature-dependent sex determination in turtles. Science 206:1186-1188

Carter AL, Kearney MR, Mitchell NJ, Hertley S, Porter WP, Nelson NJ (2015) Modelling the soil microclimate: Does the spatial or temporal resolution of input parameters matter? Front Biogeogr 7:138-154
Christopher MM, Berry KH, Wallis IR, Nagy KA, Henen BT, Peterson CC (1999) Reference intervals and physiologic alterations in hematologic and biochemical values of free-ranging desert tortoises in the Mojave Desert. J Wildl Dis 35:212-238

Ennen JR, Lovich JE, Meyer KP, Bjurlin C, Arundel TR (2012) Nesting ecology of a population of Gopherus agassizii at a utility-scale wind energy facility in southern California. Copeia 2012:222-228

> Grosse AM, Crawford BA, Maerz JC, Buhlmann KA, Norton T, Kaylor M, Tuberville TD (2015) Effects of vegetation structure and artificial nesting habitats on hatchling sex determination and nest survival of diamondback terrapins. J Fish Wildl Manag 6:19-28

> Hays GC, Fossette S, Katselidis KA, Schofield G, Ravenor MB (2010) Breeding periodicity for male sea turtles, operational sex ratios, and implications in the face of climate change. Conserv Biol 24:1636-1643

Henen BT (1997) Seasonal and annual energy budgets of female desert tortoises, Gopherus agassizii. Ecology 78: 283-296

> Janzen FJ (1994) Vegetational cover predicts the sex ratio of hatchling turtles in natural nests. Ecology 75:1593-1599

Janzen FJ, Paukstis GL (1991) Environmental sex determination in reptiles: ecology, evolution, and experimental design. Q Rev Biol 66:149-179

Karl AE (1998) Reproductive strategies, growth patterns, and survivorship of a long-lived herbivore inhabiting a temporally variable environment. PhD Dissertation, University of California, Davis, CA

Kuchling G, Griffiths O (2012) Endoscopic imaging of gonads, sex ratios, and occurrence of intersexes in juvenile captive-bred Aldabra giant tortoises. Chelonian Conserv Biol 11:91-96

Kuchling G, Goode E, Praschag P (2011) Endoscopic imaging of gonads, sex ratio and temperature dependent sex determination in captive bred juvenile Burmese star tortoises Geochelone platynota. Asian Herpetol Res 2: 240-244

Kuchling G, Goode E, Praschag P (2013) Endoscopic imaging of gonads, sex ratio, and temperature-dependent sex determination in juvenile captive-bred radiated tortoises, Astrochelys radiata. In: Castellano CM, Rhodin AGJ, Ogle M, Mittermeier RA, Randriamahazo H, Hudson R, Lewis RE (eds) Turtles on the brink in Madagascar: proceedings of two workshops on the status, conservation, and biology of Malagasy tortoises and freshwater turtles. Chelonian Res Monogr 6:113-118

Lolavar A, Wyneken J (2015) Effect of rainfall on loggerhead turtle nest temperatures, sand temperatures and hatchling sex. Endang Species Res 28:235-247

Lovich J, Agha M, Meulblok M, Meyer K and others (2012) Climatic variation affects clutch phenology in Agassiz's desert tortoise Gopherus agassizii. Endang Species Res 19:63-74

Lovich JE, Yackulic CB, Freilich J, Agha M and others (2014) Climatic variation and tortoise survival: Has a desert species met its match? Biol Conserv 169:214-224

Lovich JE, Ennen JR, Yackulic CB, Meyer-Wilkins K and others (2015) Not putting all their eggs in one basket: bet-hedging despite extraordinary annual reproductive output of desert tortoises. Biol J Linn Soc 115:399-410

> Mitchell NJ, Janzen FJ (2010) Temperature-dependent sex determination and contemporary climate change. Sex Dev 4:129-140 
Morreale SJ, Ruiz GJ, Spotila JR, Standora EA (1982) Temperature-dependent sex determination: current practices threaten conservation of sea turtles. Science 216: 1245-1247

Mueller JM, Sharp KR, Zander KK, Rakestraw DL, Rautenstrauch KR, Lederle PE (1998) Size-specific fecundity of the desert tortoise (Gopherus agassizii). J Herpetol 32: 313-319

Murphy RW, Berry KH, Edwards T, Leviton AE, Lathrop A, Riedle JD (2011) The dazed and confused identity of Agassiz's land tortoise, Gopherus agassizii (Testudines, Testudinidae) with the description of a new species, and its consequences for conservation. ZooKeys 113:39-71

Nagy KA, Hillard LS, Tuma MW, Morafka DJ (2015a) Headstarted desert tortoises (Gopherus agassizii): movements, survivorship and mortality causes following their release. Herpetol Conserv Biol 10:203-215

Nagy KA, Hillard S, Dickson S, Morafka DJ (2015b) Effects of artificial rain on survivorship, body condition, and growth of head-started desert tortoises (Gopherus agassizii) released to the open desert. Herpetol Conserv Biol 10:535-549

Patino-Martinez J, Marco A, Quinones L, Hawkes L (2012) A potential tool to mitigate the impacts of climate change to the Caribbean leatherback sea turtle. Glob Change Biol 18:401-411

Pieau CA (1976) Données récentes sur la différenciation sexuelle en function de la température chez les embryons d'Emys orbicularis L. (Chelonien). Bull Soc Zool Fr 101(Suppl):46-53

Porter WP, Mitchell JW, Beckman WA, DeWitt CB (1973) Behavioral implications of mechanistic ecology: thermal and behavioral modeling of desert ectotherms and their microenvironment. Oecologia 13:1-54

Refsnider JM, Janzen FJ (2012) Behavioural plasticity may compensate for climate change in a long-lived reptile with temperature-dependent sex determination. Biol Conserv 152:90-95

Refsnider JM, Bodensteiner BL, Reneker JL, Janzen FJ (2013) Nest depth may not compensate for sex ratio skews caused by climate change in turtles. Anim Conserv 16: $481-490$

Rostal DC (2014) Reproductive physiology of North American tortoises. In: Rostal DC, McCoy ED, Mushinsky HR (eds) Biology and conservation of North American tortoises. Johns Hopkins University Press, Baltimore, MD, p 37-45

Rostal DC, Wibbels T (2014) Embryonic development, hatching success, and temperature-dependent sex determination in North American tortoises. In: Rostal DC, McCoy ED, Mushinsky HR (eds) Biology and conservation of North American tortoises. Johns Hopkins University Press, Baltimore, MD, p 46-52

Rostal DC, Wibbels T, Grumbles JS, Lance VA, Spotila JR (2002) Chronology of sex determination in the desert tor-

Editorial responsibility: Luca Luiselli, Rome, Italy toise (Gopherus agassizii). Chelonian Conserv Biol 4: 313-318

Schwanz LE, Janzen FJ (2008) Climate change and temperature-dependent sex determination: Can individual plasticity in nesting phenology prevent extreme sex ratios? Physiol Biochem Zool 81:826-834

> Schwarzkopf L, Brooks RJ (1987) Nest-site selection and offspring sex ratio in painted turtles, Chrysemys picta. Copeia 1987:53-61

Siegel RA, Dodd CK (2000) Manipulation of turtle populations: Halfway technologies or viable options? In: Klemens MW (ed) Turtle conservation. Smithsonian Institution Press, Washington DC, p 218-238

Spotila JR, Zimmerman LC, Binckley CA, Grumbles JS and others (1994) Effects of incubation conditions on sex determination, hatching success and growth of hatchling desert tortoises. Herpetol Monogr 8:103-116

Turner FB, Hayden P, Burge BL, Roberson JB (1986) Egg production by the desert tortoise (Gopherus agassizii) in California. Herpetologica 42:93-104

US Fish and Wildlife Service (1990) Endangered and threatened wildlife and plants; determination of the threatened status for the Mojave population of the desert tortoise. Fed Regist 55:12178-12191

US Fish and Wildlife Service (1994) Desert tortoise (Mojave population) recovery plan. US Fish and Wildlife Service, Portland, OR. https://www.fws.gov/nevada/desert_ tortoise/dtro/dtro_revovery_plan.html

US Fish and Wildlife Service (2011a) Revised recovery plan for the Mojave population of the desert tortoise (Gopherus agassizii). US Fish and Wildlife Service, Pacific Southwest Region, Sacramento, CA. https://www.fws.gov/ nevada/desert_tortoise/dtro/dtro_recovery_plan.html

US Fish and Wildlife Service (2011b) Health assessment procedures for the desert tortoise (Gopherus agassizii): a handbook pertinent to translocation. Desert Tortoise Recovery Office, US Fish and Wildlife Service, Reno, NV. https://www.fws.gov/nevada/desert_tortoise/documents/ reports/2011/assess/20110506.Desert_tortoise_health_ eval_handbook.pdf

Wallis IR, Henen BT, Nagy KA (1999) Egg size and annual egg production by female desert tortoises (Gopherus agassizii): the importance of food abundance, body size, and date of egg shelling. J Herpetol 33:394-408

Wibbels T (2003) Critical approaches to sex determination in sea turtles. In: Lutz PL, Musick JA, Wyneken J (eds) The biology of sea turtles, Vol 2. CRC Press, Boca Raton, FL, p 103-134

Wibbels T (2007) Sex determination and sex ratios in ridley turtles. In: Plotkin P (ed) Biology and conservation of ridley sea turtles. Johns Hopkins University Press, Baltimore, MD, p 167-1189

Zar JH (1999) Biostatistical analysis, 4th edn. Prentice Hall, Upper Saddle River, NJ

Submitted: December 8, 2015; Accepted: April 21, 2016 Proofs received from author(s): May 22, 2016 